\title{
Outcome and Hemodynamic Alternation in Uterine Artery Following Hysteroscopic Roller-Ball Endometrial Ablation
} Abdelazim IA ${ }^{*}$, Faza $\mathrm{MA}^{2}$ and Bou Hamdan $\mathrm{S}^{3}$

${ }^{1}$ Professor of Obstetrics and Gynecology, Ain Shams University, Cairo, Egypt and Ahmadi Hospital, Kuwait Oil Company (KOC), Kuwait

${ }^{2}$ Specialist of Obstetrics and Gynaecology, Ahmadi Hospital, Kuwait Oil Company (KOC), Kuwait

${ }^{3}$ Senior of Infection control of Ahmadi Hospital, Kuwait Oil Company (KOC), Kuwait

*Corresponding author: Abdelazim IA, Professor of Obstetrics and Gynecology, Ain Shams University, Cairo, Egypt and Ahmadi Hospital, Kuwait Oil Company (KOC), Kuwait, Tel: +965-66551300, E-mail: dr.ibrahimanwar@gmail.com

Citation: Abdelazim IA, Faza MA, Bou Hamdan S (2015) Outcome and Hemodynamic Alternation in Uterine Artery Following Hysteroscopic Roller-Ball Endometrial Ablation. J Gynecol Res 1(1): 105. doi: 10.15744/2454-3284.1.105

Received Date: February 12, 2015 Accepted Date: April 25, 2015 Published Date: April 28, 2015

\begin{abstract}
Objectives: To detect the outcome and changes in uterine arteries blood flow after hysteroscopic roller-ball endometrial ablation.

Methods: 84 women with menorrhagia refused to continue or had failed medical treatment with uterine size $<12$ weeks were included in this study. Diagnostic hysteroscopy was done for women included in this study prior to endometrial ablation. A rigid operative hysteroscopy, with normal saline distention media and roller-ball electrode were used for endometrial ablation procedure. Preoperative findings of studied women including Doppler findings were compared to 3, 6 and 12 months post-operative findings to detect outcome and changes in uterine arteries blood flow after hysteroscopic roller-ball endometrial ablation.

Results: 77/84 (91.7\%) women were satisfied and their HMB was improved after rollerball endometrial ablation (33/84 (39.30\%) amenorrhea, 27/84 (32.14\%) hypo-menorrhea and 17/84 (20.24\%) euomenorrhea = normal menstrual flow). ED (End Diastolic velocity), $(9.2 \pm 7.4 \mathrm{~cm} / \mathrm{s}$ before ablation) was significantly decreased 6 and 12 months after roller-ball endometrial ablation $(5.0 \pm 6.0$ and 4.6 \pm 6.1 ; respectively), also, TAMX (Time-averaged maximum velocity), $(21.8 \pm 8.2 \mathrm{~cm} / \mathrm{s}$ before ablation) was significantly decreased 6 and 12 months after roller-ball ablation (14.8 \pm 6.4 and $13.9 \pm 6.3$; respectively). PI (Pulsatiliy Index), $(1.32 \pm 0.5 \mathrm{~cm} / \mathrm{s}$ before ablation) was significantly increased 6 and 12 months after roller-ball ablation ( $1.64 \pm 0.45$ and 1.69 \pm 0.4 ; respectively), also, RI (Resistance Index), $(0.80 \pm 0.2 \mathrm{~cm} / \mathrm{s}$ before ablation) was significantly increased 3, 6 and 12 months after roller-ball ablation $(0.84 \pm 0.4,0.89 \pm 0.2$ and $0.90 \pm 0.3$; respectively).

Conclusion: Hysteroscopic roller-ball endometrial ablation is a safe and effective therapeutic option for selected cases of menorrhagia. It increases stiffness and decreases mobility of uterine arteries during cardiac cycle, also, it induces rise in impedance with subsequent decrease in uterine blood flow and menstrual flow which completed 6-12 months following ablation procedure.
\end{abstract}

Keywords: Outcome; Hemodynamic; Uterine Arteries; Hysteroscopy; Endometrial Ablation

\section{Introduction}

Dysfunctional uterine bleeding (DUB) is a diagnosis of exclusion when there is no pelvic pathology or underlying medical cause to explain the bleeding [1]. Menorrhagia or heavy menstrual bleeding (HMB) over several consecutive cycles during reproductive years is the most frequent form of DUB. 15-20\% of women over 30 years have DUB, [1] the prevalence of DUB increases with age, and before menopause [2,3]. HMB is a significant health problem in premenopausal women, it can cause anemia and reduce quality of life [4]. Menorrhagia is one of the most common causes for referral of pre-menopausal women to gynecologists, and, inspite of medical therapy, many women will eventually require hysterectomy [4,5]. Hysterectomy is invasive option associated with significant in-patient hospitalization for many women $[4,5]$.

A large number of techniques have been developed to ablate or to remove the endometrium [4]. Hysteroscopic endometrial ablation or resection and more recently "second generation" devices such as balloon or microwave ablation offer a day-case surgical alternative to hysterectomy [6-9] The gold standard techniques (laser, trans-cervical endometrial resection and roller-ball) are safe hysteroscopic techniques for endometrial ablation, which require adequate visualization of uterine cavity and skilled surgeons [4]. Trans-vaginal Color Doppler ultrasonography enables us to discover the changes which occur in the uterine arteries blood flow after hysteroscopic endometrial ablation. This study was designed to detect the outcome and changes in uterine arteries blood flow after hysteroscopic endometrial ablation. 


\section{Patients and Methods}

Eighty four (84) women with menorrhagia (HMB) without inter-menstrual bleeding (Pictorial Blood Loss Assessment Chart) $[10,11]$ refused to continue or had failed medical treatment with uterine size $<12$ weeks were included in this study after informed consent which explained; side effects, risks, benefits of the procedures and alternative treatment options. Women included in this study were euthyroid with normal liver function tests, normal activated partial thromboplastin time (APTT) and normal platelet count. Women $<40$ years or planning for future pregnancy and women with uterine size $>12 \mathrm{~cm}$ or sub-mucus fibroid or histopathological endometrial abnormalities or abnormal Pap smear were excluded from this study. After complete history, examination and laboratory preoperative investigations, women included in this study were examined by diagnostic hysteroscopy to exclude uterine cavity abnormalities and endometrial biopsy was taken during hysteroscopy for histopathological examination prior to ablation procedure.

Endometrial preparation before ablation: based on the fact that endometrial ablation is most effective if performed when the endometrium is relatively thin or atrophic. Endometrial electrosurgical roller-ball endometrial ablations were done for all women included in this study immediately post-menstrual when endometrium is relatively thin $<4 \mathrm{~mm}$ and after preoperative curettage $[11,12]$.

Endometrial ablation procedures were done under general anesthesia, while patient in lithotomy position after insertion Foley's urinary catheter to monitor urinary output and dilatation of the cervical canal to accommodate the operative hysteroscopy. A rigid operative hysteroscopy (Olympus KeyMed, KeyMed House, Stock Road, UK), with a viewing angle 30 degree, fibro-optic Xenon 300 W (OlympusVISERS ELITE CLV-S 190) light source, camera with video recording facilities (Olympus-VISERS ELITE OTV-S 190) and external hysteroscopic sheath was used during this study. The external hysteroscopic sheath is connected to continuous inflow and outflow system (Olympus hystero-flow), to facilitating continuous distension and irrigation of uterine cavity and to monitor fluid input and output continuously (to avoid fluid overload) [13,14].

Normal saline ( $0.9 \%$ sodium chloride) in room temperature under 75-100 mmHg pressure as distention media was used during endometrial ablation procedure. An automated fluid-monitoring system was used to monitor accurately amount of normal saline deficit during ablation procedure [15]. Automated system uses the fluid weight to determine amount of fluid used, collected and then calculate the fluid deficit. It is possible to have as much as a 1 liter of normal saline deficit when using three to four 3-liters bags for irrigation. In addition, automated systems allow the surgeon to set fluid delivery pressure to uterus [16,17].

The Normal saline distension media was used in room temperature because, current researches did not show any significance of distension media warming and Olgilvie-Harris et al. concluded that women undergoing some procedures (liposuction, arthroscopy and hysteroscopy) may benefit from vasoconstriction induced by hypothermia [18,19]. $3 \mathrm{~mm}$ roller-ball electrode was used for endometrial ablation and electrosurgical bipolar current (Olympus ESG-400) was adjusted at 60-100 W. For safety, bipolar rollerball was only activated during withdrawal towards operator. Ablation was started anterior wall because accumulation of bubbles and debris in this area over time makes coagulation later more difficult, followed by lateral uterine walls including tubal orifices on both sides and finally posterior uterine walls. Ablation of cervical canal was avoided, because this may lead to stenosis of cervical canal. Postoperative follow-up was done for women included in this study till they were discharged from the hospital and repeated 3, 6 and 12 months to detect the outcome of endometrial ablation. Trans-vaginal Color Doppler measurements were obtained from main branch of uterine arteries at level of inner cervical os on both sides before electro-surgical roller-ball endometrial ablation and repeated on $1^{\text {st }}$ day, 3, 6 and 12 months after endometrium ablation to detect the changes in uterine arteries blood flow after hysteroscopic endometrial ablation. The measurements were carried out immediately post-menstrual based on the facts that; outcome of endometrial ablation is better if the endometrium is thin at time of operation and the impedance to uterine blood flow appears stable at that time of menstrual cycle [20].

All measurements were performed at the same time in the morning (because there is circadian variation in uterine blood flow impedance). Color Doppler study of uterine artery was performed using Philips HD9 with 2D convex probe 4-9 MHz (Philips Healthcare international; Amsterdam, Netherlands) by sonographer who was blinded to patients' criteria. Uterine artery was identified using Color Doppler at level of internal cervical os beside the cervix. Doppler gate was positioned on each uterine artery to detect the maximal signals. Waveforms were characterized by Peak systolic velocity (PS), ED, TAMX. The Pulsatility index (PI) and Resistance index (RI) were calculated by using the machine's built in software.

\section{Sample Size Justification}

Required sample size was calculated using $G^{*}$ Power software version 3.17 for sample size calculation ( ${ }^{*}$ Heinrich Heine Universität; Düsseldorf; Germany), setting $\alpha$-error probability at 0.05 , power ( 1 - $\beta$ error probability) at $0.95 \%$ and effective sample size (w) at 0.3. The effective size $(\mathrm{w})$ was calculated as follows: $w=\sqrt{\chi^{2 / N}}$, where $\mathrm{X}^{2}$ is the chi-square test and $\mathrm{N}$ is the total sample size. After assuming 5\% drop rate during follow up, number of participants needed to produce a statistically acceptable figure was 84 women. 


\section{Statistical Analysis}

Numerical variables were presented as mean and standard deviation, while categorical variables were presented as number and percentage. Un-paired student $(\mathrm{t})$ test used to compare numerical variables. Fisher's exact test used to compare categorical variables. A difference with $\mathrm{p}$ value $<0.05$ was considered statistically significant, otherwise it was insignificant.

\section{Results}

Mean age of women included in this study was $46.3 \pm 6.5$ years, mean parity was $6.3 \pm 4.2$, and mean body mass index (BMI) was $32.7 \pm 11.2 \mathrm{Kg} / \mathrm{m}^{2}$, mean length of uterine cavity was $10.5 \pm 2.8 \mathrm{~cm}$ and mean duration of ablation procedure was $18.36 \pm 9.5 \mathrm{minutes}$ Table 1.

\begin{tabular}{|l|l|l|}
\hline \multicolumn{1}{|c|}{ Variables } & \multicolumn{1}{c|}{ Mean \pm SD } & \multicolumn{1}{c|}{ Range } \\
\hline Age (years) & $46.3 \pm 6.5$ & $40-49$ \\
\hline Parity & $6.3 \pm 4.2$ & $3-6$ \\
\hline Body mass index $\left(\mathrm{Kg} / \mathrm{m}^{2}\right)$ & $32.7 \pm 11.2$ & $22-44$ \\
\hline Cavity length $(\mathrm{Cm})$ & $10.5 \pm 2.8$ & $8-12$ \\
\hline Duration of ablation procedure (Minutes) & $18.36 \pm 9.5$ & $15-25$ \\
\hline
\end{tabular}

Table 1: Clinical parameters of the studied population

No intra-operative complications were recorded during or after roller-ball endometrial ablation procedure in this study and all women were discharged on the $1^{\text {st }}$ day after endometrial ablation. 77/84 (91.7\%) women were satisfied and their HMB was improved after roller-ball endometrial ablation (33/84 (39.30\%) amenorrhea, 27/84 (32.14\%) hypo-menorrhea and 17/84 (20.24\%) euomenorrhea), while 7/84 (8.3\%) underwent hysterectomy because of recurrent and persistent HMB after ablation procedure.

ED $(9.2 \pm 7.4 \mathrm{~cm} / \mathrm{s}$ before ablation) was significantly decreased 6 and 12 months after roller-ball endometrial ablation (5.0 \pm 6.0 and $4.6 \pm 6.1$; respectively; $\mathrm{p}$ value $=0.03$ and 0.04 ; respectively $)$, also, TAMX $(21.8 \pm 8.2 \mathrm{~cm} / \mathrm{s}$ before ablation $)$ was significantly decreased 6 and 12 months after roller-ball ablation $(14.8 \pm 6.4$ and $13.9 \pm 6.3$; respectively; $p$ value $=0.01$ and 0.01 ; respectively). PI (1.32 \pm 0.5 $\mathrm{cm} / \mathrm{s}$ before ablation) was significantly increased 6 and 12 months after roller-ball ablation (1.64 \pm 0.45 and $1.69 \pm 0.4$; respectively; $\mathrm{p}$ value $=0.01$ and 0.02 ; respectively), also, RI $(0.80 \pm 0.2 \mathrm{~cm} / \mathrm{s}$ before ablation) was significantly increased 3,6 and 12 months after roller-ball ablation $(0.84 \pm 0.4,0.89 \pm 0.2$ and $0.90 \pm 0.3$; respectively; $\mathrm{p}$ value $=0.01,0.01$ and 0.01 ; respectively) Table 2 .

\begin{tabular}{|c|c|c|c|c|c|c|c|c|c|}
\hline Variables & Preoperative & $1^{\text {st }}$ day PO & $\begin{array}{l}\text { P1 } \\
\text { Significance } \\
\text { Test used }\end{array}$ & $\begin{array}{l}3 \text { months } \\
\text { PO }\end{array}$ & $\begin{array}{l}\text { P2 } \\
\text { Significance } \\
\text { Test used }\end{array}$ & $\begin{array}{l}6 \text { months } \\
\text { PO }\end{array}$ & $\begin{array}{l}\text { P3 } \\
\text { Significance } \\
\text { Test used }\end{array}$ & $\begin{array}{l}12 \text { months } \\
\text { PO }\end{array}$ & $\begin{array}{l}\text { P4 } \\
\text { Significance } \\
\text { Test used }\end{array}$ \\
\hline $\begin{array}{l}\text { PS }(\mathrm{cm} / \mathrm{s}) \\
\text { Mean } \pm S D\end{array}$ & $47.5 \pm 14.3$ & $46.8 \pm 13.4$ & $\begin{array}{l}0.7(>0.5) \\
\text { t-test }\end{array}$ & $46.5 \pm 10.8$ & $\begin{array}{l}0.9(>0.5) \\
\text { t-test }\end{array}$ & $45.8 \pm 11.4$ & $\begin{array}{l}0.9(>0.5) \\
\text { t-test }\end{array}$ & $45.6 \pm 11.6$ & $\begin{array}{l}0.9(>0.5) \\
\text { t-test }\end{array}$ \\
\hline $\begin{array}{l}\text { ED }(\mathrm{cm} / \mathrm{s}) \\
\text { Mean } \pm \text { SD }\end{array}$ & $9.2 \pm 7.4$ & $8.9 \pm 6.4$ & $\begin{array}{l}0.1(>0.5) \\
\text { t-test }\end{array}$ & $7.3 \pm 3.6$ & $\begin{array}{l}0(>0.5) \\
t \text {-test }\end{array}$ & $5.0 \pm 6.0$ & $\begin{array}{l}0.03^{*}(<0.5) \\
\text { t-test }\end{array}$ & $4.6 \pm 6.1$ & $\begin{array}{l}0.04^{*}(<0.5) \\
\text { t-test }\end{array}$ \\
\hline $\begin{array}{l}\text { TAMX }(\mathrm{cm} / \mathrm{s}) \\
\text { Mean } \pm \text { SD }\end{array}$ & $21.1 \pm 8.2$ & $20.8 \pm 3.6$ & $\begin{array}{l}0(>0.5) \\
\text { t-test }\end{array}$ & $17.8 \pm 4.6$ & $\begin{array}{l}0(>0.5) \\
\text { t-test }\end{array}$ & $14.8 \pm 6.4$ & $\begin{array}{l}0.01^{*}(<0.5) \\
\text { t-test }\end{array}$ & $13.9 \pm 6.3$ & $\begin{array}{l}0.01^{\star}(<0.5) \\
\text { t-test }\end{array}$ \\
\hline $\begin{array}{l}\mathrm{PI}(\mathrm{cm} / \mathrm{s}) \\
\text { Mean } \pm \text { SD }\end{array}$ & $1.32 \pm 0.5$ & $1.34 \pm 0.8$ & $\begin{array}{l}0(>0.5) \\
\text { t-test }\end{array}$ & $1.45 \pm 0.9$ & $\begin{array}{l}1(>0.5) \\
\text { t-test }\end{array}$ & $1.64 \pm 0.45$ & $\begin{array}{l}0.01^{*}(<0.5) \\
\text { t-test }\end{array}$ & $1.69 \pm 0.4$ & $\begin{array}{l}0.02^{*}(<0.5) \\
\text { t-test }\end{array}$ \\
\hline $\begin{array}{l}\text { RI }(\mathrm{cm} / \mathrm{s}) \\
\text { Mean } \pm \text { SD }\end{array}$ & $0.80 \pm 0.2$ & $0.80 \pm 0.2$ & $\begin{array}{l}0.1(<0.5) \\
\text { Fisher's test }\end{array}$ & $0.84 \pm 0.4$ & $\begin{array}{l}0.01^{\star}(<0.5) \\
\text { Fisher's test }\end{array}$ & $0.89 \pm 0.2$ & $\begin{array}{l}0.01^{\star}(<0.5) \\
\text { Fisher's test }\end{array}$ & $0.90 \pm 0.3$ & $\begin{array}{l}0.01^{\star}(<0.5) \\
\text { Fisher's test }\end{array}$ \\
\hline
\end{tabular}

Peak systolic velocity (PS), End diastolic (ED), Time-averaged maximum velocity (TAMX), Pulsatility index (PI) and Resistance index $(\mathrm{RI}){ }^{*}=$ Significant difference, $\mathrm{PO}=\mathrm{Post}-\mathrm{operative}$

$\mathrm{P} 1=1^{\text {st }}$ day post-operative Doppler measurements compared to preoperative Doppler measurements

P2 $=3$ months postoperative Doppler measurements compared to preoperative Doppler measurements

P3 $=6$ months postoperative Doppler measurements compared to preoperative Doppler measurements

P4 $=12$ months postoperative Doppler measurements compared to preoperative Doppler measurements

Table 2: Uterine artery Doppler flow before endometrial ablation, $1^{\text {st }}$ day, 3, 6 and 12 months after ablation

\section{Discussion}

Endometrial ablation is a treatment option for menorrhagia or HMB in premenopausal women when medical treatment fail, contraindicated or poorly tolerated [12]. The gold standard techniques (laser, trans-cervical resection of endometrium and rollerball) are safe hysteroscopic techniques for endometrial ablation, which require adequate visualization of uterine cavity and skilled surgeons [4]. Newer endometrial ablation techniques have recently developed, some of them under evaluation and most of them can be performed blindly, less time consuming [4].

Lethaby et al. concluded that endometrial ablation techniques play an important role in the management of HMB. The rapid development of new endometrial ablation techniques made systematic comparisons between those techniques and gold standard of trans-cervical resection of endometrium (TCRE) difficult. Most of the newer techniques are technically easier than hysteroscopybased methods, however, uterine perforation, which is the major complication of endometrial ablation, cannot be excluded without hysteroscopy [4]. 
Vilos and colleagues, concluded; that resectoscopic endometrial ablation (729 endometrial resections were done) is feasible, safe and effective treatment for simple and complex endometrial hyperplasia without atypia in women with abnormal uterine bleeding by experienced hysteroscopic surgeons [21].

In this study, no intra-operative complications were recorded during or after roller-ball endometrial ablation, 77/84 (91.7\%) women were satisfied and their HMB was improved after roller-ball endometrial ablation (33/84 (39.30\%) amenorrhea, 27/84 (32.14\%) hypo-menorrhea and 17/84 (20.24\%) euomenorrhea), while 7/84 (8.3\%) underwent hysterectomy because of recurrent and persistent $\mathrm{HMB}$ after ablation procedure. Lethaby and colleagues, found that, the operative time of roller-ball endometrial ablation is about $10-20$ minutes, with $95 \%$ patient satisfaction rate and $36 \%$ of treated patient developed amenorrhea with 12 months of postoperative follow up $[4,12]$.

Herman et al. studied the effect of bipolar endometrial ablation versus balloon ablation in HMB, and, they concluded that; the superiority of bipolar ablation over balloon ablation in treatment of HMB was no longer evident 10 years after procedures [22].

Fresno-Alba et al. found no significant differences between hysteroscopic endometrial resection versus Novasure system in terms of patients'satisfaction 3,6 and 12 months, efficacy and safety but, the mean operation time was significantly reduced to 15 minutes with Novasure, while, the final costs were higher with Novasure [23].

Penninx et al. concluded that bipolar endometrial ablation system is more effective at 5 years than hydrothermablation in treatment of menorrhagia and they also concluded that blind techniques of endometrial ablation will only work when there is direct contact between endometrial wall and ablation device, therefore, women with uteri of abnormal shape, polyps, or large size uterus $>10$ weeks size, are generally not considered candidates for this blind ablation procedures [24].

Trans-vaginal Color Doppler ultrasonography enables us to discover the changes which occur in uterine arteries blood flow after hysteroscopic endometrial ablation and this study was designed to detect the outcome and changes in uterine arteries blood flow after hysteroscopic endometrial ablation.

In this study, ED and TAMX were significantly decreased 6 and 12 months after hysteroscopic roller-ball endometrial ablation, while, PI and RI were significantly increased 6 and 12 months after roller-ball ablation. The results of this study, suggest that endometrial ablation affects uterine arteries wall by increasing its stiffness and decreasing mobility during cardiac cycle, leading to increased impedance and diminished blood flow during diastole which completed 6-12 months following ablation procedure. The increased impedance is due to decreased blood flow during diastole, because ED and TAMX were decreased, whereas PS remained unchanged. Friberge \& colleagues, concluded that; the greater the fibrosis of uterine cavity after ablation was associated with better prognosis [25]. Twenty-seven (27) women with either menorrhagia or endometrial hyperplasia without atypia, were randomized to receive either thermal balloon endometrial ablation therapy or medroxyprogesterone acetate by Dr I. Järvelä and colleagues [26]. Dr I. Järvelä and colleagues found that; the PI of uterine and spiral arteries was significantly elevated 6 months after thermal balloon endometrial ablation therapy [26]. Dr I. Järvelä et al and Asim Kurjak concluded; that endometrial ablation therapy induces a rise in uterine blood flow impedance, 6 months after treatment (not before 6 months) and the rise in impedance may be due to fibrosis in uterine cavity which occurs after ablation therapy [26,27]. In this study, no intra-operative or postoperative complications were recorded with roller-ball endometrial ablation and all women were discharged on the $1^{\text {st }}$ day after ablation procedure. Lethaby et al. concluded that hysteroscopic roller-ball endometrial ablation is safe, effective, less invasive option for treatment of menorrhagia or HMB which require adequate visualization of uterine cavity and skilled surgeons [4,28].

\section{Conclusion}

Hysteroscopic roller-ball endometrial ablation is a safe and effective therapeutic option for selected cases of menorrhagia. It increases stiffness and decreases mobility of uterine arteries during cardiac cycle, also, it induces rise in impedance with subsequent decrease in uterine blood flow and menstrual flow which completed 6 to 12 months following ablation procedure.

\section{References}

1. Vilos GA, Lefebvre G, Graves GR (2001) The Management of Uterine Leiomyomas: SOGC clinical practice guidelines No. 106. J Obstet Gynaecol Can 23: 704-9.

2. Abbott J, Hawe J, Hunter D, Garry R (2003) A double blind randomized trial comparing the Cavaterm and the NovaSure endometrial ablation systems for the treatment of dysfunctional uterine bleeding. Fertil Steril 80: 203-8.

3. Ibrahim A Abdelazim, Maha M Belal (2013) Outcome and uterine arteries Doppler velocimetry after thermal balloon endometrial ablation in menorrhagia. Evidence Based Women Health Journal (EBWHJ) 3: 35-8.

4. Lethaby A, Hickey M, Garry R (2005) Endometrial destruction techniques for heavy menstrual bleeding. Cochrane Database Syst Rev CD001501.

5. Sowter MC, Lethaby A, Singla AA (2002) Pre-operative endometrial thinning agents before endometrial destruction for heavy menstrual bleeding. Cochrane Database Syst Rev 7: CD001124.

6. Garside R, Stein K, Wyatt K, Round A, Price A (2004) The effectiveness and cost-effectiveness of microwave and thermal balloon endometrial ablation for heavy menstrual bleeding: a systematic review and economic modelling. Health Technol Assess 8: 1-155.

7. Abbott JS, Garry R (2002) The surgical management of menorrhagia. Hum Reprod Update 8: 68-78.

8. Bongers MY, Mol BW, Brolmann HA (2002) Prognostic factors for the success of TBEA in the treatment of menorrhagia. Obstet Gynecol 99: 1060-6.

9. Shamonki MI, Ziegler WF, Badger GJ, Sites CK (2000) Prediction of endometrial ablation success according to perioperative findings. Am J Obstet Gynecol 182: 1005-7. 
10. Higham JM, O’Brien PMS, Shaw RW (1990) Assessment of menstrual blood loss using a pictorial chart. Br J Obstet Gynaecol 907: 734-9.

11. O Shawki, A Peters, S Abraham-Hebert (2002) Hysteroscopic Endometrial Destruction, Optimum Method for Preoperative Endometrial Preparation: A Prospective, Randomized, Multicenter Evaluation. JSLS 6: 23-7.

12. The Practical Committee of the American Society for Reproductive Medicine (2008) Indications and options for endometrial ablation 90: S236-40.

13. Cooper JM, Brady RM (2000) Intraoperative and early postoperative complications of operative hysteroscopy. Obstet Gynecol Clin North Am 27: $347-66$.

14. Young E, Sherrard-Jacob A, Knapp K, Craddock TS, Kemper C, et al. (2009) Perioperative Fluid Management. AORN J 89: 167-82.

15. Boyd HR, Stanley C (2000) Sources of error when tracking irrigation fluids during hysteroscopic procedures. J Am Assoc Gynecol Laparosc 7: 472-6.

16. Bradley LD (2002) Complications in Hysteroscopy: Prevention, Treatment and Legal Risk. Curr Opin Obstet Gynecol 409-15.

17. Indman PD (2000) Instrumentation and distention media for the hysteroscopic treatment of abnormal uterine bleeding. Obstet Gynecol Clin North Am 27: 305-15.

18. Sessler DI (2001) Complications and treatment of mild hypothermia. Anesthesiology 95: 531-43.

19. Olgilvie-Harris DJ, Weisleder L (1995) Fluid pump systems for arthroscopies: a comparison of pressure control versus pressure and flow control. Arthroscopy 11: 591-5.

20. Zaidi J, Jurkovic D, Campbell S, Pittrof R, McGregor A, et al. (1995) Description of circadian rhythm in uterine artery blood flow during the peri-ovulatory period. Hum Reprod 10: 1642-6.

21. Vilos GA, Oraif A, Vilos AG, Ettler H, Edris F, et al. (2014) Long-term clinical outcomes following resectoscopic endometrial ablation of non-atypical endometrial hyperplasia in women with abnormal uterine bleeding. J Minim Invasive Gynecol 22: 66-77.

22. Herman MC, Penninx JP, Mol BW, Bongers MY (2013) Ten-year follow-up of a randomized controlled trial comparing bipolar endometrial ablation with balloon ablation for heavy menstrual bleeding. BJOG 120: 966-70.

23. Fresno-Alba S, DeLlera-Duarte A, Vidal-Roncero H, Usandizaga R, DeSantiago-Garcia J, et al. (2013) Endometrial ablation: comparative study between hysteroscopic resection and Novasure system. Ginecol Obstet Mex 81: 175-9.

24. Penninx JP, Herman MC, Mol BW, Bongers MY (2011) Five-year follow-up after comparing bipolar endometrial ablation with hydrothermablation for menorrhagia. Obstet Gynecol 118: 1287-92.

25. Fridberg B, Joergensen CA, Higren M (1998) Endometrial thermal coagulation degree of uterine fibrosis predicts treatment outcome. Gynecol Obstet Invest 45: 54-7.

26. I Järvelä, A Tekay, M Santala, P Jouppila (2001) Thermal balloon endometrial ablation therapy induces a rise in uterine blood flow impedance: a randomized prospective color Doppler study. Ultrasound Obstet Gynecol 17: 65-70.

27. Asim Kurjak (2008) TBEA therapy induces a rise in uterine blood flow impedance 6 months after the treatment. Donald School Textbook of Ultrasound in Obstetrics and Gynecology ( $2^{\text {nd }}$ edition) Chapter 51: 794-5.

28. Lethaby A, Hickey M, Garry R, Penninx J (2009) Endometrial resection/ablation techniques for heavy menstrual bleeding. Cochrane Database Syst Rev CD001501. 